\title{
Innovate Method for Friction Stir Welding of Al-Mg-Si Alloy Thin Plate
}

\author{
$\mathrm{Li} \mathrm{Fu}^{1,3^{*}}$ and Fenjun $\mathrm{Liu}^{1,2}$ \\ ${ }^{1}$ School of Materials Science and Engineering, Northwestern Polytechnical University, Xi'an, 710072, China \\ ${ }^{2}$ College of Energy Engineering, Yulin University, Yulin, 719000, China \\ ${ }^{3}$ State Key Laboratory of Solidification, Xi' an, 710072, China
}

\begin{abstract}
Al-Mg-Si (6061-T6) alloy with $0.8 \mathrm{~mm}$ thick plate was welded successfully by use of high speed friction stir welding (FSW) technology. The microstructural characteristics and mechanical property of the butt joints prepared by high speed FSW were analyzed in detail, the influence of welding parameters, fixture condition and after welding heat treatment were also explored. The results shown that sound surface topography and defect-free bonding interface were observed in the nugget zone (NZ). The microhardness of the as-welded joint was lower than that of the base metal because of the welding heat effect. Compared with the conventional speed FSW, the number of $\beta-\mathrm{Mg} 2 \mathrm{Si}, \mathrm{A} 12 \mathrm{CuMg}$ and $\mathrm{A} 18 \mathrm{Fe} 2 \mathrm{Si}$ precipitated phases existed in the high speed FSWed NZ increased, which made the microhardness in the NZ improved significantly. The rod-shaped precipitates $(\mathrm{Mg} 2 \mathrm{Si})$ have the greatest influence on the microhardness distributions. The maximum tensile strength of $301.8 \mathrm{MPa}$, which was $85.8 \%$ of the base metal, was obtained at high rotation speed of $8000 \mathrm{rpm}$ and fast welding speed of $1500 \mathrm{~mm} / \mathrm{min}$. The tensile strength of the ultra-high speed FSWed butt joints were improved significantly by post-weld artificial aging, with a maximum joint efficiency of $90.4 \%$.
\end{abstract}

\section{Introduction}

As a light-weight material, Heat-treatable 6xxx aluminium alloys thin plates were widely applied in the transportation industry for meeting the increasing demand for reducing weight [1]. The 6061-T6 aluminium alloy sheet welding is inevitable, when it is applied as a structural material. However, it is usually considered that this alloy is very difficult to be welded by traditional fusion welding [2].

Friction stir welding (FSW), invented by TWI, can prevent the formation of solidification structures and is capable of producing high-quality welded joints when optimized parameters are used. Therefore, in addition to riveting, FSW is considered to be one of the most effective welding methods in joining 6061-T6 aluminium alloy [3]. For FSW in heat-treatable 6061-T6 aluminium alloy, an important feature is that the conventional speed FSW technique can easily lead to the dissolution and coarsening of the precipitates in the weld zone, and ultimately affect the mechanical properties of the friction stir welded (FSWed) joints. In order to obtain higher strength FSWed 6061-T6 aluminium alloys joints, it is necessary to promote the dissolution process but impair the coarsening process of the precipitates. Thus, the thermal cycle of the FSW process would be similar to the solution heat treatment process that can improve the mechanical properties. Ramulu et al. [4] studied the influence of shoulder diameter, plunge depth, rotation speed and welding speed on the weld formation and mechanical properties of the joints, and found that the well weld formation and mechanical properties of the friction stir welded joints can be obtained due to higher heat input, caused by bigger tool shoulder diameter and plunging depth with higher rotation speed and faster welding speed. Liu et al. [5] reported that the higher rotation speed with faster welding speed can significantly increase the number of the precipitates, which further improve the mechanical properties of the FSWed 6061-T6 aluminium alloy thin plate joints. Jamshidi Aval et al. [6] found that the post-weld artificial aging (PWAA) can make the FSW joint strength equal to that of the base metal (BM), and the grain coarsening after PWAA has negligible effect on joint strength. To sum up, it seems to be an effective method to obtain the excellent mechanical properties of

\footnotetext{
*Corresponding author: fuli@nwpu.edu.cn
} 
the FSWed 6061-T6 aluminium alloy joint prepared by higher rotation speed with faster welding speed followed by PWAA.

The main purpose of present work is to prepare high mechanical properties of the FSWed Al-Mg-Si alloy thin plate joint using combination of high speed and PWAA. Thus, in an effort to investigate the effect of high speed and PWAA on microstructure characteristics and mechanical properties of the FSWed joints, a detailed analysis was done on microstructure evolution in the nugget zone (NZ) and tensile strength change of the joint.

\section{Experimental procedures}

The 0.8-mm thick 6061-T6 aluminium alloy thin plates were selected to produce the FSWed butt joints. In order to remove the oxide film, the butt surfaces of the workpieces were first mechanically ground, and then, they were cleaned with acetone and ethanol in turn. The FSW-TS-F08-DZ machine was employed to butt-weld. And the welding direction parallel to the rolling direction of the base metal (BM). The FSW tool with a triple helix shoulder $6 \mathrm{~mm}$ in diameter and a conical pin $3 \mathrm{~mm}$ and $2 \mathrm{~mm}$ in diameter at root and top, respectively, and $0.65 \mathrm{~mm}$ in length. The specific welding parameters used for the present work were listed in Table 1. The samples were labeled in abbreviated forms. For example, sample of 2000-300 means the FSWed joint obtained at rotation speed of $2000 \mathrm{rpm}$ and welding speed of $300 \mathrm{~mm} / \mathrm{min}$.

The microstructural observations were performed using an optical microscopy (OM) and transmission electron microscopy (TEM). To examine the tensile strength of the FSWed butt joints, tensile tests were carried out using the Instron 3382 electronic material universal testing machine at a crosshead speed of 1 $\mathrm{mm} / \mathrm{min}$. Meanwhile, the microhardness tests along cross-section of the FSWed joints were measured by Vickers micro-indentation.

Table. 1. Specific welding parameters and corresponding sample.

\begin{tabular}{ccc}
\hline $\begin{array}{c}\text { Rotation speed } \\
(\mathrm{rpm})\end{array}$ & $\begin{array}{c}\text { transverse speed } \\
(\mathrm{mm} / \mathrm{min})\end{array}$ & sample \\
\hline 2000 & 300 & $2000-300$ \\
8000 & 300 & $8000-300$ \\
8000 & 1500 & $8000-1500$ \\
\hline
\end{tabular}

\section{Results and discussion}

\subsection{Microstructure characteristics}

Fig. 1 shows the cross-sectional macrostructures of the FSWed 6061-T6 aluminium alloy thin plates butt joints prepared for both as-welded and PWAA joints with conventional speed $(2000 \mathrm{rpm}, 300 \mathrm{~mm} / \mathrm{min})$ and high speed $(8000 \mathrm{rpm}, 1500 \mathrm{~mm} / \mathrm{min})$. It is clear from the figure that defect-free bonding interface was detected in the NZ. In other words, the well FSWed 6061-T6 thin plate joints were successfully produced using both conventional speed and high speed. It also indicates that the proper heat input, moderate stirring action and material plastic deformation are beneficial to the balanced material flow, which is an ideal welding state without welding defect during FSW process [7].

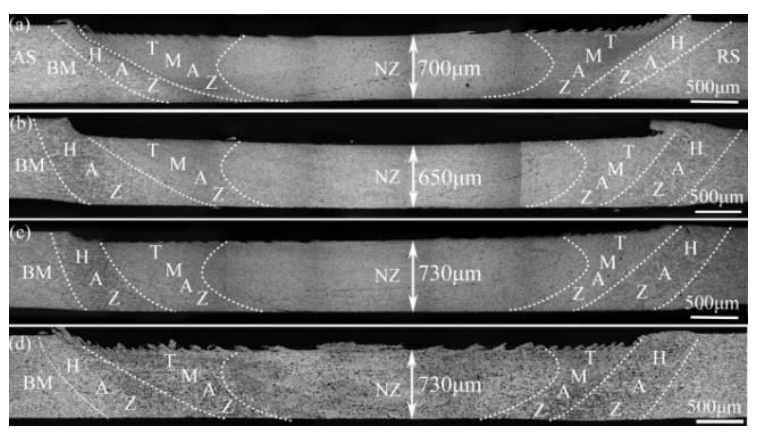

Fig. 1. Macrostructures of the FSWed 6061-T6 joints prepared for (a) 2000-300, (b) 8000-300, (c) 8000-1500, (d) 8000-1500-PWAA.

In order to reveal the microstructure characteristics of the NZ prepared for as-welded and PWAA joints under different welding parameters, TEM were applied to observe, as shown in Fig. 2. It can be seen that, in the high rotation speed $(8000 \mathrm{rpm})$ FSW process, the number and size of the Al8Fe2Si and Al2CuMg in the $\mathrm{NZ}$ were larger than that of low rotation speed (2000 $\mathrm{rpm})$. The precipitates size of $\mathrm{Mg} 2 \mathrm{Si}$ and $\mathrm{Al} / 8 \mathrm{Fe} 2 \mathrm{Si}$ in the NZ obtained at fast welding speed $(1500 \mathrm{~mm} / \mathrm{min})$ was smaller than that of low transverse speed (300 $\mathrm{mm} / \mathrm{min}$ ) under high rotation speed process. After PWAA, the number of precipitates in the NZ was obviously increased due to the re-precipitation of unstable and metastable saturated solid solutions. In addition, it can be seen that the dramatic enhancement of dislocation density and substructure in the NZ after PWAA, as shown in Fig. 3. 

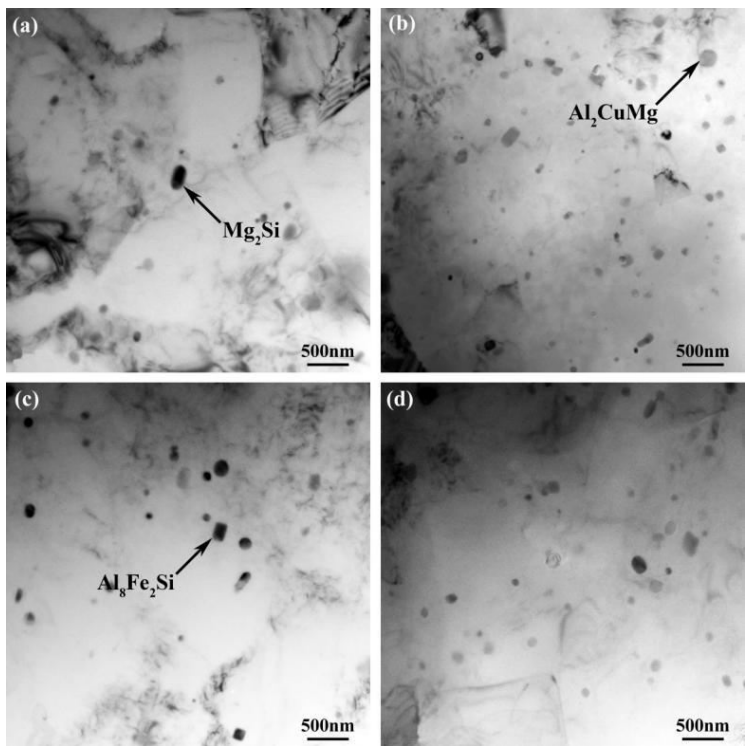

Fig. 2. Distribution of precipitate in the NZ (a) 2000-300, (b) $8000-300$, (c) 8000-1500, (d) 8000-1500-PWAA.
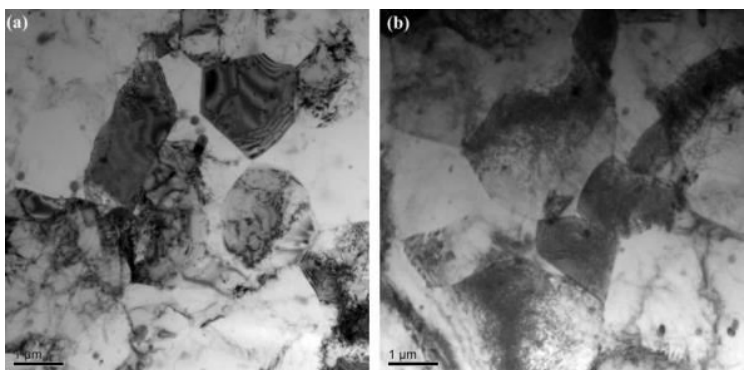

Fig.3. Dislocation distribution of the NZ (a) 8000-1500, (b) 8000-1500-PWAA.

\subsection{Microhardness}

Fig. 4 shows the microhardness distributions of the FSWed 6061-T6 aluminium alloy thin plates butt joints prepared for both as-welded and PWAA under different welding parameters. It can be seen that the hardness distributions exhibit the typical characteristics of a "W" shape in all joints. A wide low-hardness zone (LHZ) in all the FSWed butt joints was observed. The hardness in the LHZ of the FSWed joints obtained at high rotation speed was significantly improved compared to the low rotation speed. In addition, it also clearly seen that the hardness distribution was affected slightly by further increases the transverse speed during high rotation speed FSW. After PWAA, a large number of precipitates and substructures were reformed in the weld zone, which resulting in improving the hardness in the LHZ significantly. The minimum hardness value $(83.5$ $\mathrm{HV}$ ) of the high rotation speed FSWed joint was located in the advancing side heat affected zone (HAZ), which was $130.5 \%$ of the low rotation speed FSWed joint (64.0 HV).

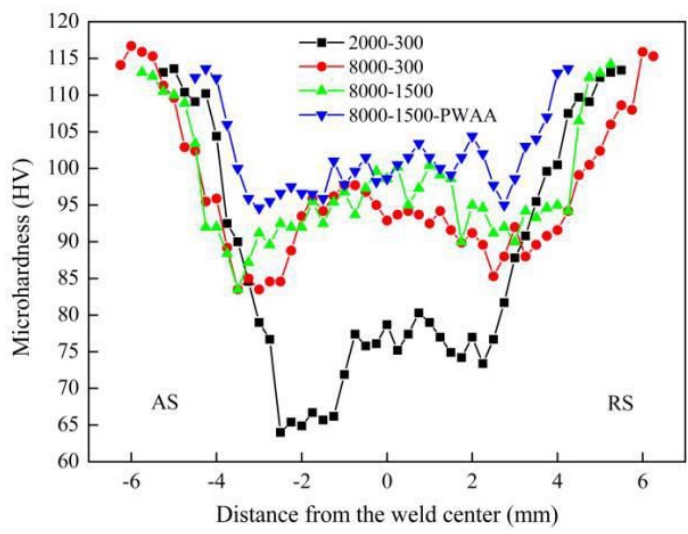

Fig. 4. Microhardness distributions of the FSWed joints along the cross sections.

\subsection{Tensile properties}

Fig. 5. shows the tensile properties of the BM and the FSWed 6061-T6 aluminium alloy thin plates butt joints prepared for both as-welded and PWAA under different processing parameters. It can be found that the tensile properties of all the FSWed joints were lower than that of the BM. The tensile properties of the FSWed joints obtained at high rotation speed were better than that of low rotation speed. The tensile strength and yield strength of the FSWed joints were increased with increasing the welding speed during high rotation speed FSW. After PWAA, the maximum tensile strength (317.8 $\mathrm{MPa}$ ) of the high speed FSWed joint was obtained, which was about $90.4 \%$ of the BM.

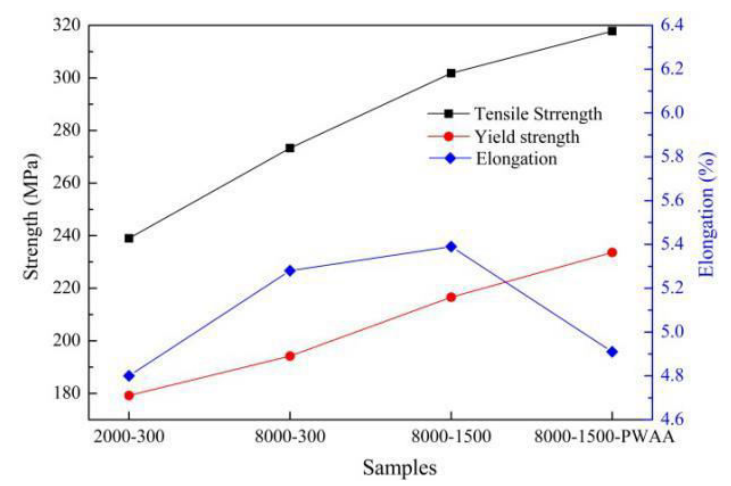

Fig. 5. Tensile properties of the FSWed 6061-T6 joints.

\section{Conclusion}

Sound FSWed 6061-T6 aluminium alloy thin plates butt joints could be produced at both low rotation speed and high rotation speed under air-cooling condition. A large number of precipitates and subgrains in the NZ were obtained at high rotation speed FSW technology, and exhibited little difference by further increasing the transverse speed. After PWAA, the number of precipitates and subgrains was significantly increased. The excellent mechanical properties of the FSWed 6061-T6 aluminium alloy thin plates joints were 
produced using high rotation speed and fast welding speed combined with PWAA.

This work was supported by the National Natural Science Foundation of China (No. 51575450 and 51861034); the Natural Science Foundation of Shaanxi Province (No. S2016YFJZ0164 and 2018GY-129); and the Research Fund of the State Key Laboratory of Solidification Processing (No. 127-QP-2015).

\section{References}

1. W.S. Miller, L. Zhuang, J. Bottema, A.J. Wittebrood, P. De Smet, A. Haszler, A. Vieregge, Mater. Sci. Eng. A 280 (2000)

2. X.H. Zhan, J.C. Chen, J.J. Liu, Y.H. Wei, J.J. Zhou, Y. Meng, Mater. Des. 99 (2016)

3. S. Malopheyev, I. Vysotskiy, V. Kulitskiy, S. Mironov, R. Kaibyshev, Mater. Sci. Eng. A 662 (2016)

4. P.J. Ramulu, R.G. Narayanan, S.V. Kailas, Int. J. Adv. Manuf. Technol 69 (2013)

5. F.J. Liu, L. Fu, H.Y. Chen, Acta. Metall. Sin 53 (2017)

6. M. Mahdi Moradi, H. Jamshidi Aval, R. Jamaati, J. Manuf. Process 30 (2017)

7. W.J. Arbegast, Scr. Mater 58(2008) 